\title{
Avaliação de quarta geração: atendimento aos familiares de usuários de crack
}

Fourth generation evaluation: care for family of crack users

Evaluación de cuarta generación: atención a los familiares de usuarios de crack

\section{Maria de Lourdes Custódio Duarte ${ }^{\mathrm{I}}$, Leticia Passos Pereira ${ }^{\mathrm{II}}$, Agnes Olschowsky ${ }^{\mathrm{II}}$ Juliana de Carvalho ${ }^{I V}$}

Resumo: Objetivo: conhecer a avaliação dos profissionais de um Centro de Atenção Psicossocial Álcool e Drogas III (CAPS) sobre o atendimento ofertado aos familiares de usuários de crack. Método: estudo qualitativo, com referencial da Avaliação de Quarta Geração. Os dados foram coletados de junho a setembro de 2013, com 15 profissionais de um CAPS, por meio de entrevistas e observações, com análise pelo método comparativo constante, originando o eixo temático Atendimento aos familiares de usuários de crack. Resultados: o atendimento ofertado às famílias foi avaliado como fundamental no processo de tratamento, contando com o Atendimento Individual, Grupo de Família, Visita Domiciliar e Acolhimento como espaços relevantes. Considerações finais: evidenciou-se a importância de espaços heterogêneos de inclusão da família nos serviços substitutivos, além da necessidade dos profissionais buscarem qualificar ainda mais o atendimento a essas famílias.

Descritores: Saúde mental; Pesquisa sobre Serviços de Saúde; Cocaína crack; Família

Abstract: Aim: to know the evaluation of the professionals of a Centro de Atenção Psicossocial Álcool e Drogas III (CAPS) about the care offered to family members of crack users. Method: qualitative study, with reference to the

\footnotetext{
${ }^{\text {I }}$ Enfermeira. Doutora em Enfermagem. Professora Adjunta do curso de Enfermagem da Universidade Federal do Rio Grande do Sul. Porto Alegre, RS, Brasil. E-mail: malulcd@yahoo.com.br ORCID: 0000-0001-6307-3942

II Enfermeira. Mestranda do Programa de Pós Graduação em Enfermagem da Universidade Federal do Rio Grande do Sul. Porto Alegre, RS, Brasil. E-mail: leti_passos@msn.com ORCID:0000-0002-9260-3794

III Enfermeira. Doutora em Enfermagem Psiquiátrica. Professora Titular do curso de Enfermagem da Universidade Federal do Rio Grande do Sul. Porto Alegre, RS, Brasil. E-mail: agnes@enf.ufrgs.br ORCID: 0000-0003-1386-8477

IV Enfermeira. Mestranda do Programa de Pós Graduação em Enfermagem da Universidade Federal do Rio Grande do Sul. Porto Alegre, RS, Brasil. E-mail: juli.carvalho.pf@hotmail.com ORCID: 0000-0002-6388-1402
} 
Avaliação de quarta geração: atendimento aos familiares de usuários de crack | 2

Fourth Generation Assessment. The data were collected from June to September 2013, with 15 professionals from a CAPS, through interviews and observations, with analysis by constant comparative method, originating the thematic axis Attendance to the relatives of users of crack. Results: the care offered to the families was evaluated as fundamental in the treatment process, counting on Individual Care, Family Group, Home Visit and Reception as relevant spaces. Final considerations: the importance of heterogeneous spaces of inclusion of the family in the substitutive services was evidenced, besides the necessity of professionals seeking to qualify the service to these families even more.

Descriptors: Mental Health; Health Services Research; Crack Cocaine; Family

Resumen: Objetivo: conocer la evaluación de los profesionales de un Centro de Atención Psicosocial Alcohol y Drogas III (CAPS) sobre la atención ofrecida a los familiares de los usuarios de crack. Método: estudio cualitativo, con referencial basado en la Evaluación de Cuarta Generación. Los datos fueron recolectados de junio a septiembre de 2013, con 15 profesionales de un CAPS, por medio de entrevistas y observaciones, y el análisis por método comparativo constante originó el eje temático Atención a los familiares de usuarios de crack. Resultados: la atención ofrecida a las familias fue evaluada como fundamental en el proceso de tratamiento, y el Servicio Individual, el Grupo de Familia, la Visita Domiciliaria y Acogida como espacios relevantes en el CAPS. Consideraciones finales: se evidenció la importancia de espacios heterogéneos de inclusión de la familia en los servicios sustitutivos, además de la necesidad de los profesionales calificaren aún más la atención a esas familias.

Descriptores: Salud mental; Investigación en servicios de salud; Cocaína crack; Familia

\section{Introdução}

Atualmente, o crack vem sendo considerado um problema de saúde pública no Brasil e no mundo devido a sua alta incidência na população. Isso ocorre pelo seu potente efeito recompensador, de curta duração, estimulando a administração repetida, de tal forma que, depois de sua experimentação, deflagra-se o uso intenso e compulsivo, passando ele a desempenhar papel central na vida do usuário, ou seja, torna-se prioritário em detrimento de comportamentos que antes tinham relevância. ${ }^{1}$ 
No início dos anos de 1990, no Brasil, menos de 10\% das internações de dependentes químicos eram de usuários de crack, no entanto no final da década esse número subiu para $80 \%{ }^{2}$ Em dados relacionados ao uso de drogas ilícitas nos EUA, a cocaína aparece como a principal responsável pelas internações hospitalares, e, dentre as formas de uso da cocaína nesse mesmo país, o crack é a forma mais utilizada. ${ }^{3}$

O uso compulsivo do crack interfere na dimensão individual do usuário, comprometendo também seu relacionamento social, de forma que os vínculos sociais e familiares estáveis se fragilizam e se rompem progressivamente. A dificuldade no convívio entre usuário e familiares é caracterizada como um dos vários obstáculos a serem enfrentados em relação ao uso do crack. $^{4-5}$

Frente a isso, a família, enquanto um núcleo de cuidado e de parceira nas ações de saúde para o enfrentamento do uso abusivo e dependência do crack, deve também ser percebida pelas equipes de saúde como uma unidade que requer atenção e assistência, frente ao desgaste físico e emocional gerado na família pela droga. Assim, os membros do núcleo familiar necessitam de atenção, acolhimento, informação a fim de que possam se fortalecer, auxiliando seu familiar em recuperação.

Dessa forma, visualiza-se que a família possui um papel essencial no processo terapêutico pois, quando passa a inserir-se no cotidiano dos serviços, consegue compreender o contexto das drogas e suas especificidades, consequentemente entende as necessidades do usuário. ${ }^{6-7}$

No contexto dos serviços de saúde mental, destacam-se os Centros de Atenção Psicossocial Álcool e Drogas III (CAPS AD III), serviços especializados que proporcionam a atenção integral e contínua às pessoas com necessidades relacionadas ao consumo de álcool, crack e outras drogas, com funcionamento nas 24 horas do dia e em todos os dias da semana, inclusive finais de semana e feriados. ${ }^{8}$ 
Os CAPS devem envolver a família no tratamento do usuário de crack, procurando dar suporte a esta, para superar as dificuldades no enfrentamento do uso da droga e da carga emocional gerada nos familiares de usuários de crack. ${ }^{9}$

Dentre as inúmeras estratégias de apoio, de inserção e de estimulo à participação do familiar no tratamento do usuário de crack nos CAPS AD, destacam-se atendimento individual, acolhimento, visita domiciliar, oficinas e grupos de familiares. Estas atividades podem auxiliar na convivência com os usuários, no fortalecimento dos familiares e no aprendizado para lidar com as situações decorrentes do uso de substância, uma vez que na dependência do crack os valores pessoais e sociais são fragilizados pela centralidade que a substância passa a ter na vida dos usuários.

Desse modo, questiona-se: qual a avaliação dos trabalhadores de um CAPS AD III sobre o atendimento destinado aos familiares de usuários de crack na perspectiva da Avaliação de Quarta Geração?

Pretende-se com este estudo contribuir no avanço do conhecimento científico no campo da saúde mental, em especial quanto às demandas relacionadas ao consumo de crack na região investigada, dando subsídios para avançar nas ações de saúde que consideram a família como protagonista de cuidado. Assim, entende-se que o referencial da avaliação de Quarta Geração pode fazer emergir o empoderamento dos profissionais como protagonistas das mudanças necessárias para a qualificação dos CAPS AD no atendimento dos familiares de usuários de crack.

Neste estudo serão apresentados dados parciais da pesquisa intitulada "Familiares dos usuários de Crack em um CAPS AD III: avaliação das necessidades de cuidados”10 no qual utilizou-se o referencial da Avaliação de Quarta Geração. Tem-se o objetivo de conhecer a avaliação dos profissionais de um CAPS AD III sobre o atendimento ofertado aos familiares de usuários de Crack. 


\section{Método}

Este estudo foi realizado em um CAPS AD tipo III com dois anos de funcionamento, localizado na fronteira oeste do Estado do Rio Grande do Sul, Brasil, sendo referência de atendimento para 125.435 habitantes. 11

Trata-se de uma pesquisa que utilizou o referencial teórico metodológico da Avaliação de Quarta Geração ${ }^{12}$ de abordagem hermenêutica-dialética e de cunho construtivista e responsivo.

A Avaliação de Quarta Geração é implementada por meio dos pressupostos metodológicos do paradigma construtivista. Trata-se de uma avaliação responsiva, em que as reivindicações, preocupações e questões dos grupos de interesse servem como foco organizacional (a base para determinar que informação seja necessária). Constitui-se como uma importante possibilidade metodológica no campo da saúde mental, na medida em que possibilita que sejam acessadas dimensões pouco passíveis de serem apreendidas por medições e indicadores. Além disso, uma metodologia participativa permite um controle do processo e dos resultados da avaliação compartilhados pelos avaliadores e pelos grupos de interesse. ${ }^{13}$

A abordagem hermenêutica-dialética é hermenêutica por possibilitar a interpretação dos dados construídos por meio das subjetividades e é dialético porque propõe discussão de diferentes pontos de vista, de modo a obter um resultado avaliativo mais próximo à realidade no qual as opiniões são produzidas. Já o enfoque responsivo, usa as reinvindicações, preocupações e questões dos grupos de interesse (stakeholder) como aspectos que direcionam todo o processo avaliativo. $^{12}$

A coleta de dados ocorreu no período de junho a setembro de 2013 e contou com 15 profissionais designados como grupos de interesse da totalidade de 30 trabalhadores que o serviço contava naquele período. Participaram da coleta de dados quatro psicólogos, três cuidadores, dois técnicos de enfermagem, três oficineiras, uma terapeuta ocupacional, um enfermeiro e um médico, com carga horária de 40 horas semanais de trabalho. Destes, 12 eram 
Avaliação de quarta geração: atendimento aos familiares de usuários de crack I 6

do sexo feminino e 10 encontravam-se entre os 30 anos e 49 anos. Nove não possuíam formação em saúde mental ou dependência química.

Como critérios de inclusão dos profissionais, estabeleceram-se: atuar no serviço há mais de seis meses e prestar cuidados diretos a pessoas usuárias de crack e sua família, pois entendese que esse período seja suficiente para que o trabalhador possa fazer uma avaliação do atendimento destinado aos familiares de usuários de crack. Foram excluídos do estudo dez profissionais que possuíam menos de seis meses de serviço e cinco que estavam afastados por férias e licenças saúde.

Para a consolidação do processo de avaliação qualitativa, a coleta de dados seguiu os pressupostos teóricos e metodológicos da Quarta Geração ${ }^{12}$ que se resumem em: Contato com o campo (quando foram realizadas reuniões com a equipe do serviço para discorrer sobre a proposta da pesquisa); Identificação dos Stakeholders (neste estudo foram considerados os profissionais); Desenvolvimento e ampliação das construções conjuntas (aplicação do círculo hermenêutico-dialético); Apresentação dos dados para os grupos de interesse (realizada a partir do processo de negociação, que consistiu na organização das construções conjuntas, validação das informações e verificação de consensos) e, construção dos resultados finais do processo avaliativo (realizado após a negociação).

A coleta de dados foi realizada por meio de observação e entrevista individual áudiogravada, estabelecida por meio do círculo hermenêutico-dialético.

Com base no círculo hermenêutico-dialético, a primeira entrevista foi realizada com o respondente 1 chamado de $\mathrm{R} 1$, e ao final de sua entrevista, o mesmo foi solicitado a indicar outro respondente, designado como R2, a fim de que este pudesse apontar novas formulações. Contudo, antes da entrevista com o R2, os temas, conceitos, ideias, valores, preocupações e questões centrais, propostos por R1, foram sintetizados, por meio da escuta do áudio da entrevista, a fim de extrair os pontos relevantes que possibilitassem a construção 1 (C1) que 
7 I Duarte MLC, Pereira LP, Olschowsky A, Carvalho J

serviu de fonte de informações para proceder a entrevista com o R2 que também foi convidado, ao final de sua entrevista, a indicar um novo respondente R3.

Para tanto, a entrevista com R2 possibilitou uma nova construção, designada como C2, que por sua vez, serviu para direcionar a entrevista com o respondente 3 (R3) e assim, sucessivamente. Como respondente inicial (R1) do círculo de profissionais, foi eleito aquele com maior tempo de atuação no serviço.

A reunião de contato com o campo foi realizada em março de 2013. Em junho foi dado início a observação, que consistiu, em um primeiro momento, na aproximação da pesquisadora com a dinâmica de cuidado estabelecida no serviço, totalizando 150 horas. Neste momento, denominado etnografia prévia, o objetivo é que o avaliador conheça o serviço sem ainda estar engajado na atividade de avaliação. ${ }^{12}$ Após foi iniciada uma observação mais sistematizada do atendimento aos familiares de usuários de crack, totalizando 150 horas. Esta etapa permite que o avaliador possa conhecer com maior profundidade o objeto a ser avaliado, auxiliando em uma compreensão das questões apresentadas pelo grupo de interesse no círculo hermenêuticodialético. A observação pode também permitir que o avaliador identifique temas/questões que julgue relevantes a serem apresentadas para os participantes para que se manifestem em relação a elas. Todas as observações foram registradas em um diário de campo das 300 horas de observações.

A etapa de entrevista, mediante aplicação do círculo hermenêutico-dialético já descrito, foi iniciada no mês de agosto e finalizada em setembro. A entrevista com o primeiro integrante da equipe foi orientada por um roteiro semiestruturado, contendo as seguintes questões: $\mathrm{Na}$ sua opinião, como ocorre o atendimento aos familiares de usuários de crack aqui no CAPS? Quais são os espaços ofertados para esse atendimento?

Para a análise do conteúdo das entrevistas foi utilizado o Método Comparativo Constante, ${ }^{12}$ que consiste em analisar os dados, por meio da escuta dos depoimentos logo após a 
sua coleta para, assim, identificar as construções de cada respondente e apresentar o conteúdo das entrevistas precedentes nas entrevistas posteriores, a fim de realizar novas formulações acerca das questões apontadas nos depoimentos.

Com a finalização de todo o círculo hermenêutico-dialético, as entrevistas foram transcritas na íntegra. Dessa maneira foi iniciada a fase de organização e análise dos resultados prévios a serem apresentados na reunião de negociação que serviu para a construção de consensos acerca do grupo. Esta ocorreu por meio de agendamento prévio e contou com o comparecimento dos 15 entrevistados.

Para esse momento, foi produzido um material impresso, contendo a síntese dos dados das entrevistas, sendo este entregue a cada profissional entrevistado. Após, foi realizada explanação dos resultados obtidos nas entrevistas, pelo avaliador, por meio de apresentação com auxílio de Power Point, objetivando a discussão, validação e negociação dos dados, como eixo prioritário da avaliação.

O papel do avaliador consiste em realizar uma avaliação em que todos os envolvidos, por meio do diálogo e da negociação, possam chegar a um consenso frente às reivindicações, preocupações e questões enfrentadas naquele momento. Isto posto, há uma interação e reintegração da avaliação. ${ }^{14}$

Após a etapa de negociação, os dados foram reorganizados com base nas construções e consensos estabelecidos pelo grupo de interesse, para serem descritos, neste estudo, em forma de eixos temáticos. O eixo temático desenvolvido neste artigo foi denominado Atendimento aos familiares de usuário de crack, oriundo das unidades de significados: Atendimento Individual, Grupo de Família, Visita Domiciliar, Acolhimento.

As observações possibilitaram que o avaliador incluísse questões nas entrevistas e também levaram a um entendimento analítico mais profundo daquelas apresentadas pelos próprios entrevistados. Além disso, tem-se na negociação final, um momento coletivo de 
9 | Duarte MLC, Pereira LP, Olschowsky A, Carvalho J

reconstrução deste conjunto de informações que possibilita tanto o seu aprofundamento quanto o seu ajuste.

Foi utilizado o Termo de Consentimento Livre e Informado em duas vias, de acordo com a Resolução 466/2012 do Conselho Nacional de Saúde, que aprova diretrizes e normas regulamentadoras de pesquisa envolvendo seres humanos. ${ }^{15}$ Este estudo foi aprovado pelo Comitê de Ética em Pesquisa da Universidade Federal do Rio Grande do Sul (UFRGS), com o Parecer número 75635. Para garantia do anonimato dos participantes, os excertos dos depoimentos estão identificados com a letra $\mathrm{P}$ (profissional) seguidos de um número indicativo da sequência em que as entrevistas foram realizadas e; de uma breve caracterização dos sujeitos.

\section{Resultados}

Os entrevistados avaliaram o atendimento ofertado às famílias de usuários de crack como fundamental no apoio ao tratamento e elencaram o atendimento individual, a visita domiciliar, o grupo de apoio e o acolhimento como espaços de atenção e de fortalecimento. Esses espaços de atendimento fortalecem a inserção das famílias no serviço, auxiliando-as em um momento conturbado no início do tratamento e de relação entre familiar e usuários estremecidas em decorrência do uso de Crack.

Os profissionais avaliaram o atendimento individual como um espaço importante aos familiares de usuários de Crack, tendo em vista que muitas famílias preferem um momento individualizado, que permita privacidade ao desabafar com o profissional de saúde sobre aspectos pessoais relacionado ao usuário de drogas, sem exposição.

$O$ atendimento individual acredito que seja um dos atendimentos mais importantes porque ai é que a gente consegue descobrir o que que está acontecendo com a familia. (E5) 
Avaliação de quarta geração: atendimento aos familiares de usuários de crack | 10

Tem familiares, principalmente os de usuário de crack, que tem vergonha de contar algo nos grupos e por isso preferem o atendimento individual. (E8)

Teve uma familiar que mesmo estimulada a falar no grupo, não verbalizou sua história, apenas disse que falaria no atendimento individual suas dúvidas e receios. (OBSdia10).

O atendimento individual ofertado aos familiares de usuários de crack no CAPS AD surge como um espaço de cuidado, principalmente em momentos de crise. Além disso, muitas famílias não estão e/ou não se sentem preparadas para lidar com as dificuldades oriundas do uso do crack e por isso, podem preferir um espaço mais individualizado com o profissional do serviço.

A visita domiciliar foi avaliada pelos profissionais do CAPS AD como um espaço importante para o cuidado da família e o usuário de crack, tendo em vista que proporciona observação da dinâmica familiar, acompanhamento do usuário no seu território, apoio e busca ativa de faltosos nas atividades do serviço.

Alguns casos especiais que a gente vê necessidade, a gente faz o acompanhamento domiciliar desse familiar. Caso aconteça algum tipo de intercorrência, a gente faz também. Quem vem uma vez só no grupo e depois não vem mais, a gente tem que tá procurando pra saber porque que não veio, indo atrás, telefonando, fazendo visita na casa. (E9)

Acho muito importante fazer as visitas para essas famílias e usuários de crack para acompanhar a realidade, eu acho que é melhor ir na casa mesmo, para conhecer onde ele vive, onde ele mora, o que faz, o que deixa de fazer. (E10)

Acompanhei uma visita domiciliar e percebi o quanto é importante para o estreitamento de vínculos entre profissionais, usuários e familiares. $A$ profissional do CAPS questionou porque o familiar não tem comparecido no serviço. (OBS dia 7) 
Outro espaço verbalizado pelos entrevistados foi o acolhimento. O acolhimento é um momento de escuta e permite a identificação de demandas de cuidado dos familiares dos usuários de crack, na qual a equipe pode fazer orientações e fazer encaminhamentos em um ambiente seguro, privativo e sigiloso. Esse acolhimento requer do profissional uma escuta qualificada para lidar com as demandas trazidas por esses familiares.

Quando a gente faz o acolhimento, a gente vê o que precisa, se precisa marcar uma consulta ou não, faz uma escuta e qualquer um pode fazer esse primeiro acolhimento. Mas não deve ser fácil para o familiar desses usuários chegarem aqui no serviço e se expor e contar tudo, por isso é mais sigiloso. (E8)

$\grave{A} s$ vezes, o familiar vem com o problema do crack, mas dentro desse problema tem outros que o profissional que está na linha de frente senão tiver um preparo para atender essas familias vai deixar muita coisa escapar e tu não vai conseguir resgatar esse usuário e família. (E13)

No CAPS AD são ofertados quatro grupos de familiares, cada um com uma média de 15 familiares no turno da manhã, tarde e noite na tentativa de oportunizar diversos horários. Assim, os entrevistados avaliaram a existência de grupos como um espaço importante de cuidado destinado aos familiares de usuários de drogas, dentre eles o crack.

Eu acho que o tratamento em grupo é muito válido, um está sempre ajudando o outro com suas experiências. A gente ajuda também, dá orientações, a gente fala o quanto é importante a familia estar inserida neste contexto, fala a mesma linguagem. Eu acho que tem bastante resultado, a familia é bem parceira. A gente tem sempre um espelhamento, trazendo ao grupo um problema que é comum a todos. (E15) 
Avaliação de quarta geração: atendimento aos familiares de usuários de crack | 12

É bom os grupos porque eles trocam experiências com outro, porque eles possuem o mesmo problema. Sempre é uma coisa boa. Eles falam: "Faz assim! Não faz assim porque assim não dá certo”. (E10)

Registra aí que nós aqui do CAPS disponibilizamos quatro horários de grupos aos familiares porque sabemos a importância desse espaço para essas familias que ficam muito fragilizadas com o crack no cotidiano. (Negociação)

No entanto, os entrevistados avaliaram a necessidade de preparo e formação dos coordenadores dos grupos destinados aos familiares de usuários de crack tendo em vista que o trabalho em grupo exige dos profissionais conhecimento de técnicas de grupo que vão além da formação acadêmica.

A gente não tem nenhuma técnica por que a gente não teve formação para isso. O que eu sei de grupo são aqueles que eu vi na faculdade, acho que a gente deveria fazer uma capacitação para atender este grupo. (E15)

Nós deveríamos ter um curso, uma capacitação de como fazer grupo, pois a maioria dos profissionais daqui não possui esse conhecimento. (Negociação)

Além destes, também é importante considerar a aquisição de conhecimentos relacionados a dependência química, inerente ao cuidado em um CAPS AD, tornando possível a execução de grupos com qualidade nesses serviços.

\section{Discussão}

Os usuários de crack são mais propensos a abandonar o tratamento tendo em vista problemas com a lei e a baixa habilidade social de enfrentamento, ${ }^{16}$ Assim, espaços de atendimento individual no CAPS são importantes no fortalecimento dos familiares nesse contexto repleto de desafios. Além do estabelecimento de vínculo, o atendimento individual ao familiar é oportuno para o esclarecimento do papel dos familiares no tratamento da 
13 I Duarte MLC, Pereira LP, Olschowsky A, Carvalho J

dependência química. Em estudo apresentado, ${ }^{17}$ os familiares têm ciência do seu papel no tratamento, buscando estarem próximos do serviço. Dessa forma, a disponibilização de espaços em que os familiares se sintam apoiados estabelece uma relação de parceria entre estes e a equipe, fortalecendo a inserção da família nos serviços.

É imprescindível que os familiares recebam orientações sobre as repercussões que o uso de crack pode acarretar, pois quanto mais estiverem informados, maiores são as chances de entenderem que a sua presença no serviço de saúde mental vai para além de um pedido de auxílio pontual e se configura em uma parceria que deve se efetivar, tanto nas fases de instabilidade, quanto nas de equilíbrio. ${ }^{17-18}$

A visita domiciliar surge como uma ferramenta que permite que o profissional compreenda o contexto dos usuários e seus familiares. Além disso, o acesso ao domicílio e à comunidade como um todo, pode propiciar que os trabalhadores do CAPS conheçam outros pontos de cuidado disponíveis ao usuário e família, os quais fazem parte da rede de apoio local. ${ }^{19}$ O conhecimento do contexto e da rede qualificam o atendimento prestado pelo serviço, uma vez que possibilita a realização de abordagens condizentes com a dinâmica familiar e a articulação com os demais pontos de cuidado. Dessa maneira, o recurso da visita domiciliar torna-se também importante ao permitir que o profissional se atente à realidade da família e busque compreender e auxiliar em suas demandas e necessidades de saúde e de cuidado.

Esta estratégia deve dar ênfase à humanização do atendimento, gerando vínculos entre usuário, equipe e família, promovendo o protagonismo da família no cuidado ao usuário de crack. Esse dispositivo de assistência pode ser uma boa perspectiva para que a equipe preste cuidado humano, criativo, sensível e longe da internação hospitalar ${ }^{20}$ Nessa perspectiva, a visita domiciliar exige dos profissionais do serviço de saúde empenho para que se efetive com qualidade, resultando em apoio à família, que é acompanhada em seu território. 
Outra forma de atendimento no CAPS AD aos familiares foi o acolhimento, entendido com um dispositivo para garantir maior acesso dos usuários e familiares aos serviços de saúde, facilitar a constituição de vínculos por meio de escuta genuína das demandas em uma perspectiva de cuidado integral, humanizado e resolutivo. ${ }^{21} \mathrm{O}$ familiar que chega ao serviço buscando ajuda espera ter suas demandas atendidas e, para este fim, o acolhimento serve como partida. Tratando-se de um primeiro momento de atendimento, destaca-se a importância do profissional se colocar à disposição para efetivamente acolher e proporcionar um momento de confiança, empatia e possíveis encaminhamentos.

Nessa perspectiva, propõe-se um redirecionamento das ações, tornando-as de responsabilidade de toda a equipe, promovendo a integração de saberes e práticas, ampliando sua resolubilidade, a partir de uma lógica usuário-centrada. ${ }^{22}$ A realização do acolhimento sob este entendimento requer que a equipe se sinta preparada para acolher as demandas dos familiares, executar escuta ativa e planejar encaminhamentos. Estas habilidades dos profissionais podem ser desenvolvidas e se iniciam pela inserção da lógica centrada no usuário e seu familiar, como uma realidade no serviço. Dessa maneira, o acolhimento e a escuta, enquanto tecnologias leves são dispositivos fundamentais para resolubilidade do cuidado em saúde mental, pois facilitam a permanência do usuário e seu familiar no serviço e, consequentemente, no tratamento. ${ }^{18} \mathrm{O}$ acolhimento surge, então, como espaço primordial na criação de vínculos entre equipe e familiares.

Os grupos de apoio aos familiares de usuários de crack configuraram-se no serviço estudado como espaços de cuidado possibilitando um momento no qual as famílias podem compartilhar os problemas entre si, sendo esta uma forma de se sentirem incluídas no tratamento, colaborando na superação das dificuldades inerentes ao uso de crack. ${ }^{9,17}$

Assim, a atividade grupal se torna um instrumento essencial para os familiares de usuários de crack, pois os auxilia a conviverem com os problemas em decorrência do uso dessa 
substância, aprendendo a manejá-los de modo mais saudável. ${ }^{9}$ Melhorar as relações familiares por meio dos grupos de apoio é resgatar a família novamente como um fator de proteção na prevenção de recaídas e na continuidade do tratamento, estimulando a motivação do usuário a seguir o plano de cuidados construído pelos profissionais do CAPS AD. ${ }^{9}$

O coordenador do grupo dimensiona o tempo de fala de cada integrante e é fundamental o conhecimento sobre a dependência química e suas consequências para a oferta de um cuidado com qualidade, garantindo segurança ao profissional nesse atendimento.

Sendo assim, o coordenador do grupo necessita de entendimento de seu papel nesse espaço em uma abordagem prática-teórica, no sentido de aplicá-lo como instrumento de ensinoaprendizagem que possibilite a reflexão de conceitos e conflitos pessoais. ${ }^{23}$ Esse momento permite ao indivíduo estabelecer um processo de mudanças para resoluções, encontrando seu próprio caminho, por meio das reflexões que surgem durante a participação no grupo. ${ }^{24-25}$ Assim, a aplicação de técnicas grupais pelo profissional coordenador do grupo com familiares pressupõe empatia e conhecimento do tema do uso de drogas, em especial o uso de crack, o que facilita a interação do profissional com os familiares e a resolução de conflitos.

\section{Considerações finais}

Ao longo do processo de investigação e pela análise e discussão dos resultados, buscou-se uma resposta para o problema de pesquisa que foi o de conhecer a avaliação dos trabalhadores de um CAPS AD sobre o atendimento destinado aos de familiares de usuários de crack na perspectiva da avaliação de Quarta Geração.

No decorrer deste trabalho, evidenciou-se que o atendimento destinado aos familiares de usuários de crack no serviço constitui-se em quatro espaços: Atendimento Individual, Grupo de Família, Visita Domiciliar e Acolhimento. 
O atendimento individual a esses familiares foi avaliado como um espaço importante, tendo em vista que muitas famílias preferem um momento com privacidade para desabafar e contar aspectos da sua vida cotidiana com o usuário sem exposição.

Outro espaço de atendimento ofertado pelo serviço estudado foram os Grupos de apoio aos familiares de usuários de crack. Os profissionais avaliaram que a disponibilidade de quatro horários de grupos facilita a participação dessas famílias e estimula sua inserção no serviço. No entanto, os entrevistados avaliam a necessidade de formação dos coordenadores de grupos, tendo em vista que o trabalho em grupo exige dos profissionais conhecimento da técnica para além do que foi adquirido na Universidade. Dessa maneira, cabe a esses profissionais buscar qualificação para a coordenação dos grupos.

O acolhimento e a visita domiciliar foram avaliados como espaços que proporcionam espaços de escuta das demandas de saúde e de cuidado ofertado a esses familiares, no qual a equipe pode fazer orientações e encaminhamentos em um ambiente privativo e que proporciona aproximação entre profissionais e famílias nos momentos de crise.

A partir destes resultados percebe-se a importância de espaços heterogêneos de inclusão da família nos serviços, no entanto, que não se esgotem naqueles aqui apresentados. A inserção e participação da família devem ser pensadas e problematizadas de acordo com os contextos, sem "fórmulas” prontas, favorecendo a abertura e a aproximação com estas famílias de acordo com as possibilidades e realidades singulares.

Como caráter inovador dessa pesquisa destaca-se a utilização do método de Avaliação de Quarta Geração já que este referencial teórico-metodológico, que abarca a pesquisa construtivista, com enfoque formativo e responsivo, faz emergir o empoderamento dos trabalhadores como protagonistas das transformações necessárias ao aprimoramento do serviço.

O envolvimento dos trabalhadores na avaliação do atendimento aos familiares de usuários de crack oportunizou que a experiência deste grupo fosse considerada no sentido de 
17 I Duarte MLC, Pereira LP, Olschowsky A, Carvalho J

produzir conhecimento relativo às práticas da atenção psicossocial no CAPS AD, a partir do seu cotidiano, muitas vezes desconsiderado em avaliações tradicionais.

Ressalta- se que este estudo tem como limitação abranger dados referentes a um serviço específico e por isso, não possibilita generalizações. Ainda, considera-se que o processo hermenêutico dialético é dinâmico, havendo informações que poderiam ter sido mais contempladas nas discussões do processo avaliativo, no entanto, o fator tempo de realização do estudo interferiu no processo da pesquisa.

Portanto, salienta-se a importância dos profissionais desses serviços substitutivos com ênfase no álcool, crack e outras drogas buscarem qualificar ainda mais o atendimento a essas famílias. Dessa maneira, há a urgência das instituições de ensino e de saúde investirem na discussão e na qualificação de profissionais, dentre eles o enfermeiro, evidenciando o potencial desse trabalhador nesses serviços.

\section{Referências}

1. Seleghim MR, Inoue KC, Santos JAT, Oliveira MLF. Aspectos da estrutura familiar de jovens usuários de crack: um estudo do genograma. Ciênc Cuid Saúde [Internet]. 2011 [acesso em 2014 mar 10];10(4):795802. Disponível em: http://dx.doi.org/10.4025/cienccuidsaude.v10i4.18325.

2. Acioli Neto ML, Santos MFS. As máscaras da pobreza: o crack como mecanismo de exclusão social. Psicol Estud [Internet]. 2015 [acesso em 2016 jun 10];20(4):611-23. Disponível em: http://dx.doi.org/10.4025/psicolestud.v20i4.28292.

3. Pedrosa SM, Reis ML, Gontijo DT, Teles AS, Medeiros M. A trajetória da dependência do crack: percepções de pessoas em tratamento. Rev Bras Enferm [Internet]. 2016 [acesso em 2017 maio 16];69(5):956-63. Disponível em: http://dx.doi.org/10.1590/0034-7167-2016-0045.

4. Fertig A, Schneider JF, Oliveira GC, Olschowsky A, Camatta MW, Pinho LB. Mulheres usuárias de crack: conhecendo suas histórias de vida. Esc Anna Nery Rev Enferm [Internet]. 2016 [acesso em 2017 jan 05];20(2):310-6. Disponível em: http://dx.doi.org/10.5935/1414-8145.20160042.

5. Romanini M, Roso A. Mídia e crack: promovendo saúde ou reforçando relações de dominação? Psicol Ciênc Prof [Internet]. 2012 [acesso em 2013 abr 05];32(1):82-97. Disponível em: http://dx.doi.org/10.1590/S1414-98932012000100007. 
6. Horta ALM, Daspett C, Egito JHT, Macedo RMS. Vivência e estratégias de enfrentamento de familiares de dependentes. Rev Bras Enferm [Internet]. 2016 [acesso em 2017 jan 05];69(6):1024-30. Disponível em: http://dx.doi.org/10.1590/0034-7167-2015-0044.

7. Oliveira EN, Santana MMG, Eloia SC, Almeida PC, Felix TA, Ximenes Neto FRG. Projeto terapêutico de usuários de crack e álcool atendidos no centro de atenção psicossocial. Rev Rene [Internet]. 2015 [acesso em 2016 jul 15];16(3):434-41. Disponível em: http://www.periodicos.ufc.br/rene/article/view/2819.

8. Brasil. Ministério da Saúde. Portaria n. 130/GM, de 26 de janeiro de 2012. Redefine e estabelece diretrizes para o funcionamento dos Centros de Atenção Psicossocial de Álcool e Outras Drogas $24 \mathrm{~h}$ (CAPS III) e os respectivos incentivos financeiros [Internet]. Brasília (DF);2012 [acesso em 2013 jul 10 ]. Disponível em: http://bvsms.saude.gov.br/bvs/saudelegis/gm/2012/prt0130_26_01_2012.html.

9. Duarte MLC, Vianna KR, Olschowsky A. Avaliação dos usuários de crack sobre os grupos de familiares no centro de atenção psicossocial. Cogitare Enferm [Internet]. 2015 [acesso em 2016 jul 17];20(1):81-8. Disponível em: http://dx.doi.org/10.5380/ce.v20i1.37597.

10. Duarte MLC. Familiares dos usuários de crack em um CAPS AD III: avaliação das necessidades de cuidados [tese]. Porto Alegre: Universidade Federal do Rio Grande do Sul; 2013. 205 p.

11. Instituto Brasileiro de Geografia e Estatística (IBGE). Censo 2010: estimativas das populações residentes segundo os municípios [Internet]. Rio de Janeiro (RJ); 2010. [acesso em 2017 ago 08]. Disponível em: http://cidades.ibge.gov.br/xtras/perfil.php?codmun=432240.

12. Guba E, Lincoln Y. Avaliação de quarta geração. Campinas: Unicamp; 2011.

13. Kantorski LP, Wetzel C, Olschowsky A, Jardim VMR, Bielemann VLM, Schneider JF. Avaliação de quarta geração: contribuições metodológicas para avaliação de serviços de saúde mental. Interface (Botucatu) [Internet]. 2009 [acesso em 2016 jul 10];13(31):343-55. Disponível em: http://www.scielo.br/scielo.php?script=sci_arttext\&pid=S1414-32832009000400009.

14. Andrade RS; Viana KSL. Atividades experimentais no ensino da química: distanciamentos e aproximações da avaliação de quarta geração. Ciênc Educ (Bauru) [Internet]. 2017 jun [acesso em 2016 jul 10];23(2):507-22. Disponível em: http://www.scielo.br/pdf/ciedu/v23n2/1516-7313-ciedu-23-02-0507.pdf.

15. Brasil. Ministério da Saúde. Conselho Nacional de Saúde. Resolução n. 466, de 12 de dezembro de 2012. Diretrizes e Normas Regulamentadoras sobre pesquisas envolvendo seres humanos. Brasília (DF): Ministério da Saúde; 2012.

16. Xavier RT, Monteiro JK. Tratamento de pacientes usuários de crack e outras drogas nos CAPS AD. Psicol Rev [Internet]. 2013 [acesso em 2016 jul 10];22(1):61-82. Disponível em: https://revistas.pucsp.br/index.php/psicorevista/article/view/16658.

17. Lima MS, Aguiar ACL, Sousa MM. O cuidado compartilhado em saúde mental como potencial de autonomia do usuário. Psicol Estud [Internet]. 2015 [acesso em 2016 set 21];20(4):675-86. Disponível em: http://dx.doi.org/10.4025/psicolestud.v20i4.28309. 
18. Jorge MSB, Vasconcelos MGF, Castro Junior EF, Barreto LA, Rosa LRS, Lima LL. Resolubilidade do cuidado em saúde mental na Estratégia Saúde da Família: representação social de profissionais e usuários. Rev Esc Enferm USP [Internet]. 2014 [acesso em 2016 set 21];48(6):1062-8. Disponível em: http://dx.doi.org/10.1590/S0080-623420140000700014.

19. Duarte LC, Fernandes M, Schmalfuss JM. Facilidades e dificuldades na realização de visitas domiciliares em um centro de atenção psicossocial. Cogitare Enferm [Internet]. 2014 [acesso em 2015 fev 07];19(3):451-8. Disponível em: http://dx.doi.org/10.5380/ce.v19i3.34340.

20. Lima GZ, Feltrin JA, Rodrigues JJ, Buriola AA. Percepção de acadêmicos de enfermagem sobre o cuidado em saúde mental em domicílio: uma abordagem qualitativa. Rev Pesqui cuid Fundam [Internet]. 2016 [acesso em 2017 mar 08];8(2):4255-68. Disponível em: http://dx.doi.org/10.9789/2175-5361.2016.v8i2.4255-4268.

21. Rigotti DG, Garcia APRF, Silva NG, Mitsunaga TM, Toledo VP. Acolhimento de usuários de drogas em Unidade Básica de Saúde. Rev Rene [Internet]. 2016 [acesso em 2017 mar 08];17(3):346-54. Disponível em: http://periodicos.ufc.br/rene/article/view/3465/2707.

22. Minóia NP, Minozzo F. Acolhimento em saúde mental: operando mudanças na atenção primária à saúde. Psicol Ciênc Prof [Internet]. 2015 [acesso em 2017 maio 11];35(4):1340-9 . Disponível em: http://dx.doi.org/10.1590/1982-3703001782013.

23. Dall'Agnol CM, Magalhães AMM, Mano GCM, Olschowsky A, Silva FP. A noção de tarefa nos grupos focais. Rev Gaúcha Enferm [Internet]. 2012 [acesso em 2014 abr 21];33(1):186-90. Disponível em: http://dx.doi.org/10.1590/S1983-14472012000100024.

24. Lucchese R, Calixto BS, Vera I, Paula NI, Veronesi CL, Fernandes CNS. O ensino de práticas grupais em enfermagem norteado pelo referencial de Pichon-Rivière. Esc Anna Nery Rev Enferm [Internet]. 2015 [acesso em 2016 set 21];19(2):212-9. Disponível em: http://dx.doi.org/10.5935/1414-8145.20150027.

25. Santos LF, Oliveira LMAC, Munari DB, Peixoto MKAV, Barbosa MA. Fatores terapêuticos em grupo de suporte na perspectiva da coordenação e dos membros do grupo. Acta Paul Enferm [Internet]. 2012 [acesso em 21 abr 2014];25(1):122-7. Disponível em: http://dx.doi.org/10.1590/S0103-21002012000100021.

\section{Autor correspondente}

Maria de Lourdes Custódio Duarte

E-mail: malulcd@yahoo.com.br

Endereço: R. São Manoel, 963 - Rio Branco, Porto Alegre - RS

CEP: 90620-110

\section{Contribuições de Autoria}

1 - Maria de Lourdes Custódio Duarte

Concepção e planejamento do projeto de pesquisa, análise e interpretação dos dados, redação e revisão crítica. 
Avaliação de quarta geração: atendimento aos familiares de usuários de crack | 20

2 - Leticia Passos Pereira

Análise e interpretação dos dados, redação e revisão crítica.

3 - Agnes Olschowsky

Concepção e planejamento do projeto de pesquisa, análise e interpretação dos dados, redação e revisão crítica.

4 - Juliana de Carvalho

Análise e interpretação dos dados, redação e revisão crítica.

\section{Como citar este artigo}

Duarte MLC, Pereira LP, Olschowsky A, Carvalho J. Avaliação de quarta geração: atendimento aos familiares de usuários de crack. Rev. Enferm. UFSM. 2019 [Acesso em: 2019 jun 15];vol ex:1-20. DOI:https://doi.org/10.5902/2179769229057 